\title{
UMA REFLEXÃO SOBRE O USO DAS DROGAS E A EUTANÁSIA
}

DOI: $10.22289 / 2446-922 X . V 2 E E A 1$

\author{
José Ribeiro Fiusa ${ }^{1}$ \\ Gilmar Antoniassi Júnior
}

\section{RESUMO}

A correlação existente entre a finitude da vida por vias naturais e a decorrente dos maus hábitos dos indivíduos nos propõe uma reflexão acerca da situação em que se encontram os usuários de droga. Acredita-se que dentre as principais dificuldades diante do tema morte esteja a aceitação do paciente e de seus familiares das condições impostas pela doença, o que se torna um gerador de conflito e adoecimento no núcleo familiar. O objetivo deste trabalho é promover uma reflexão entre a eutanásia, o abuso das drogas e o impacto familiar. O estudo será do tipo qualitativo, de base bibliográfica, a fim de promover uma discussão integrativa envolvendo a temática relacional das drogas e da família. Foram selecionados 23 artigos no período compreendido entre os anos 2000 e 2015. Conclui-se que os problemas decorrentes do uso das drogas e a morte constituem uma questão geradora de angústia e sofrimento para a família e o sujeito envolvido no problema, pois se busca a recuperação do ser amado e frustra-se diante das incertezas e da sensação de impotência ao deparar-se com uma condição irreversível de uma doença ou deterioração física.

Palavras-Chave: Uso de Drogas; Eutanásia; Família.

\section{ABSTRACT}

The correlation between the finitude of life by natural means and the finitude deriving from the bad habits of individuals propose a reflection on the situation the drug users are in. It is believed that the main difficulties in the face of the subject of death are the acceptance of patients and their families of the conditions imposed by the disease, which becomes a conflict and illness generator in the family nucleus. The aim of this study is to promote a reflection among euthanasia, drug abuse and the impact in the family. The study is of qualitative type of a bibliographic database in order to promote an integrative discussion on the subject of drugs and family. 23 articles were selected in the period of 2000 to 2015. The study concludes that the problems derived from the use of drugs and death constitute a generating matter of anguish and suffering of the family and the subject involved in the problem, as the family seeks the recovery of the beloved and is frustrated before the uncertainty and the feeling of helplessness when faced with an irreversible condition of a disease or physical deterioration.

Keywords: Drug Use; Euthanasia; Family.

\footnotetext{
1Endereço eletrônico de contato: joseribeiropsicologia@hotmail.com
}

Outubro, 2016:2(Edição Especial):1-13. 


\section{INTRODUÇÃO}

No Brasil a eutanásia é considerada um crime contra a vida, partindo-se do pressuposto de que a morte deve acontecer naturalmente, sem interferência de terceiros (1). No entanto, a palavra eutanásia tem origem grega e significa boa morte, no sentido de colocar um fim ao sofrimento, passando a impressão de que é um falecimento sereno e sem dor para o enfermo. Dessa forma, a eutanásia é um método cogitado para pacientes que se encontram em estado vegetativo ou de extremo sofrimento devido a alguma doença em estado terminal (2).

O Brasil convive com outro problema no âmbito da saúde: o consumo de drogas. Os danos causados ao organismo pelo uso excessivo de substâncias psicoativas e a desestruturação familiar, causada pelo usuário, deixam clara a necessidade de ações voltadas para a prevenção do seu uso, tais como a abolição de rótulos discriminatórios, a promoção da saúde, respeitando os direitos humanos, a reinserção social do usuário, além do suporte à família do mesmo (3).

A família funciona como uma organização. Quando um membro adoece, é comum que outras pessoas também se acometam, fazendo com que a família precise se reorganizar. $A$ reação dos familiares contribuirá com a forma de reação do paciente; eles necessitam ter a consciência de que a doença não desestabilizou totalmente o lar e precisam desfrutar de alguns momentos de lazer para que possam se preparar, gradativamente, para o momento no qual o doente não estará mais presente (4).

Ao submeter-se a uma internação, o indivíduo se insere em uma situação que escapa ao seu próprio controle, aceitando que sua saúde seja entregue às mãos daqueles que estão no estabelecimento propício ao tratamento; ele perde sua liberdade e precisa adaptar-se às rotinas do local, o que lhe traz uma vivência nova e estranha (5).

O contato com a morte se dá principalmente no contexto hospitalar, que por vezes reflete uma realidade dura para paciente e familiares, a partir do momento em que o enfermo se transforma em um número de leito e passa a ser identificado a partir deste ou da patologia pela qual foi acometido (6).

O presente estudo se justifica pela percepção rotineira dos problemas decorrentes do uso de drogas na sociedade contemporânea e por conhecer uma história de sofrimento e dilema familiar em torno da eutanásia. A questão norteadora deste estudo deu-se a partir da seguinte indagação: seria o abuso das drogas uma forma de praticar a eutanásia?

Desta forma, o objetivo deste trabalho é promover uma reflexão sobre a relação entre a eutanásia e o abuso das drogas frente ao envolvimento familiar.

Outubro, 2016:2(Edição Especial):1-13. 
Averígua-se que as dentre as principais dificuldades diante do tema morte esteja a aceitação do paciente e de seus familiares das condições impostas pela doença e da partida do ente querido, que exige uma reestruturação do ambiente familiar. No que concerne ao tema eutanásia, as questões que surgem são relacionadas ao poder de decisão sobre a própria vida e à dos demais, surgindo dúvidas sobre até que ponto é possível interferir no percurso vivencial dos indivíduos.

A correlação entre a finitude da vida por vias naturais e a decorrente dos maus hábitos dos indivíduos nos propõe uma reflexão acerca da situação em que se encontram os usuários, indivíduos que buscam o refúgio momentâneo de seus problemas em substâncias que degradam suas vidas paulatinamente.

Alude-se que a degradação da saúde desses indivíduos seria uma forma de eutanásia, na qual, por meio de suas próprias ações, irão liquidando periodicamente sua qualidade de vida em aspectos físicos e mentais.

\section{MÉTODOS}

O estudo é do tipo qualitativo de base e revisão teórico-bibliográfica, intentando-se promover uma discussão integrativa em torno da temática das drogas e da família. Foram utilizados os seguintes descritores: drogas; família; eutanásia, para a combinação e associação dos cruzamentos, objetivando promover o levantamento do material fundamentador do presente estudo.

A coleta de dados foi realizada por meio seletivo de publicações científicas procedentes de bases de dados digitais como SCIELO, organizações governamentais e não governamentais, no período compreendido entre os anos 2000 e 2015.

Dos dados coletados foram selecionados 22 artigos, os quais foram examinados sistematicamente de modo a identificar os descritores, objetivos, principais resultados e as conclusões apresentadas pelos autores. A análise dos dados coletados resultou em sínteses que possibilitaram reflexão e discussão da temática.

\section{CONCEITO DE EUTANÁSIA}

Em certo ditado popular afirma-se: "a única certeza que se tem nesta vida é a de que um dia deixar-se-á de viver; a morte chegará sem avisar para cada ser vivente sobre a Terra".

Outubro, 2016:2(Edição Especial):1-13. 
Essa consciência de morte iminente, consequentemente, faz com que os indivíduos pensem mais a respeito de suas vidas e de como querem viver seus dias até o momento do último suspiro. A morte é um tema de difícil abordagem, visto que nenhum indivíduo estando em boas condições físicas e mentais quer deixar de viver (7).

Examinando por outra ótica, há os casos nos quais os indivíduos já não possuem o mínimo de qualidade de vida devido a doenças altamente debilitantes e irreversíveis. Desses aspectos pode surgir, tanto para o indivíduo quanto para seus familiares, o conceito de eutanásia (8).

A eutanásia é uma forma de interrupção da vida do indivíduo em casos em que este já não possui chances de se recuperar. Tal procedimento pode ser realizado com o consentimento do paciente ou de seus familiares e será sempre realizado por um médico. É considerada uma morte digna, pois interrompe o sofrimento daquele encontrado em estado vegetativo e sem chances de cura (9). O conceito de eutanásia divide-se em eutanásia ativa, a qual ocorre quando o médico se utiliza de algum procedimento para colocar fim à vida do indivíduo enfermo e a eutanásia passiva, que consiste em uma omissão através da qual se deixa de realizar procedimentos prolongadores da vida do paciente; em ambos os casos deve haver o consentimento do paciente e/ou de seus familiares (10).

No Brasil a eutanásia é considerada um crime contra a vida, pressupondo que a morte deve se dar naturalmente, sem interferência de terceiros (1). No entanto, a palavra eutanásia tem origem grega e significa boa morte, no sentido de colocar um fim ao sofrimento, passando a impressão de que é uma morte cômoda e sem sofrimento para o doente. Dessa forma, a eutanásia é um método cogitado para pacientes que se encontram em estado vegetativo ou de extremo sofrimento devido a alguma doença, já em estado terminal (2).

Existem tipos diferentes de eutanásia, tais como:

- Eutanásia voluntária: ocorre por meio da vontade do paciente que deixa claro a seus familiares e médicos que prefere aderir ao procedimento ao invés de prosseguir com tratamentos dolorosos diante de um quadro irreversível;

- Eutanásia involuntária: ocorre quando o procedimento é realizado sem o consentimento do paciente;

- Eutanásia não-voluntária: quando a morte se dá sem que se conheça a verdadeira vontade do paciente (9).

A eutanásia se diferencia do suicídio assistido, segundo dedução de que na eutanásia nem sempre o indivíduo está consciente do procedimento; por exemplo, ele pode estar em coma e sendo mantido vivo através de equipamentos hospitalares que serão Outubro, 2016:2(Edição Especial):1-13. 
desligados, ocasionando a morte. No suicídio assistido o indivíduo solicita a ajuda de outra pessoa para morrer; ele se encontra consciente e manifesta sua opção pela morte (9).

\section{USO DE DROGAS NA CONTEMPORANEIDADE}

A Organização Mundial da Saúde (OMS) define droga como qualquer substância não produzida pelo organismo que é capaz de alterar o funcionamento de um ou mais de seus sistemas, gerando alterações no seu funcionamento. Essas substâncias dividem-se em duas categorias: as drogas lícitas e ilícitas. No campo da licitude encontram-se aquelas cuja produção e comercialização são permitidas por lei. Nessa categoria encontram-se o álcool, tabaco medicamentos e outras. Já ilícitas são todas as substâncias que têm sua produção e comercialização proibidas por força da legal. (9).

As drogas são classificadas em três tipos de acordo com o efeito que produzem no organismo do indivíduo que as consome. As drogas depressoras (ex.: heroína) geram intensa sensação de prazer, mas devem ter seu uso repetido para amenizar a sensação de carência que surge durante o período de abstinência da substância. Já as drogas estimulantes (ex.: cocaína) causam um misto de euforia e autoconfiança. Por último, as drogas alucinógenas (ex.: haxixe) geram efeitos de bem-estar, sonolência, desequilíbrios motores, alucinações e paranoias (12).

Segundo dados divulgados pela Organização das Nações Unidas (ONU), dentre as drogas mais consumidas mundialmente estão a maconha, cocaína, ópio, heroína, haxixe, ecstasy, LSD, crack, lança-perfume e o speedball, que é uma mistura de heroína com anfetaminas ou cocaína (9).

São vários os motivos que podem levar um indivíduo a consumir substâncias psicoativas, ou seja, aquelas capazes de alterar seu estado de consciência. Dentre esses motivos pode-se destacar a curiosidade por experimentar sensações novas, a vontade de fugir da realidade, mesmo que por alguns instantes, e as influências sociais (13).

O abuso de substâncias psicoativas prejudica a saúde física e mental daquele que a consome, bem como atrapalha o seu convívio em sociedade. As drogas afastam os indivíduos de si mesmos e de seus entes queridos, fragilizando as relações existentes entre eles (14).

Dentre o leque de problemas que podem surgir em decorrência do uso de drogas, realçam-se no âmbito físico a hipertensão, pancreatite, úlcera, cardiopatia, cirrose e enfisema pulmonar. No tocante aos prejuízos psicológicos causados por essas substâncias, ressaltamse os transtornos de humor, ansiedade, psicose e insônia. Esses dois aspectos podem gerar

Outubro, 2016:2(Edição Especial):1-13. 
afastamentos ou perda de emprego, dificuldades de relacionamento com familiares e amigos, acidentes e problemas jurídicos, influenciando também o lado social da vida do indivíduo (12).

As famílias dos usuários de drogas sofrem diretamente os efeitos de tal consumo, visto que vivenciam o distanciamento do ente querido, presenciam comportamentos agressivos durante o período de abstinência, veem a deterioração e as perdas do indivíduo enquanto buscam fazer com que o mesmo aceite ajuda para se tratar. Deduz-se notório que o ambiente familiar também inspira cuidados para que não se torne uma atmosfera adoecida. Ao mesmo tempo em que deve ser entendida como parte fundamental para a efetividade do tratamento dos usuários, a família deve ser fortalecida para agir como fator de proteção na prevenção e assistência no tratamento dos usuários (15).

A participação familiar na recuperação de dependentes químicos ultrapassa o simples acompanhamento do indivíduo em órgãos de recuperação. A família atua apoiando o usuário financeiramente, visto que em alguns casos o mesmo pode ter perdido tudo o que tinha em função das drogas. Deve ser geradora de diálogo e afeto, agindo como alicerce material, moral e psicológico. (16).

O tratamento de dependentes químicos pode contemplar o atendimento ambulatorial, internações breves e longas, atendimento psicoterápico com apoio farmacológico, acompanhamento terapêutico em centros de convivência e deverá ser organizado na forma de dispositivos específicos com atribuições previamente estabelecidas. É necessário criar no indivíduo a consciência dos danos causados por tais substâncias em seu organismo, para que ele se submeta ao tratamento e se deixe influenciar pela verdade, evitando possíveis recaídas após o término do processo (12).

Os usuários de drogas contam com auxílio para se tratar, por meio de programas viabilizados pelo Ministério da Saúde, como o Centro de Atenção Psicossocial Álcool e Drogas (CAPS AD), cuja estrutura oferece tratamento humanizado vinculado a uma rede de atenção em saúde e assistência integral, proporcionando apoio familiar e reinserção social (17).

\section{DISCUSSÃO}

As discussões sobre o uso das drogas têm repercutido em todas as camadas sociais. Interpretado como uma doença, a possibilidade também de eutanásia tem se manifestado. São muitos os fatores que envolvem o debate sobre drogas, o uso e suas consequências, bem como a eutanásia como recurso ao sofrimento nos casos de comprovada irreversibilidade patológica. Em todas as situações, a família encontra-se em evidência no poder de decisão, seja diante da morte pela eutanásia ou da tentativa de fazer algo para livrar o sujeito dos problemas com as drogas.

Outubro, 2016:2(Edição Especial):1-13. 
Todavia, o diagnóstico de paciente terminal é complexo e gera um choque tanto ao indivíduo acometido quanto a seus familiares, pois deixa claro que não há cura para a enfermidade que acometeu o ente. Antes de receber tal diagnóstico, é provável que esse indivíduo já tenha sido submetido a diversos tratamentos dolorosos e geradores de efeitos colaterais que deixaram seu organismo debilitado (4).

Sensações semelhantes são vivenciadas entre aqueles que descobrem a presença de um usuário de drogas no seio familiar. Diante de tal fato, esta estrutura sofre um abalo inicial, buscando-se os culpados e há a sensação de desespero sobre o que fazer para ajudar o indivíduo a se afastar do vício. A família irá priorizar aquilo que for melhor para prestar auxílio a seu componente, que, neste caso, será a sua abstinência de substâncias psicoativas e sua reinserção social, visando à recuperação de um estilo de vida saudável (18).

A presença de um usuário de drogas no ambiente familiar gera sofrimento devido à existência do laço afetivo com o usuário e ao sentimento de responsabilidade solidária pela formação do indivíduo. Em uma família cuja existência de vícios ainda era inexistente, é comum surgir o sentimento de culpa nos pais, que buscam entender quando e como falharam na formação do caráter de seu filho, fazendo com que ele se tornasse um dependente químico (19).

O envolvimento com as drogas afeta a autoestima dos genitores. Dessa forma, tornamse comuns os conflitos emocionais, a depressão, o sentimento de medo e as incertezas relacionadas ao prognóstico e ao tratamento, ocasionando uma sobrecarga familiar (20).

Entendida como basilar para o desenvolvimento do indivíduo, a família tem o sofrimento agravado quando é responsabilizada pela sociedade por qualquer anormalidade que possa romper com a expectativa social de seus membros devido a algum desvio. (19).

Embora o uso das drogas revele a ideia da morte do usuário, quando este se encontra em estado de degradação avançado, num primeiro momento a família nega o fato do uso, porém percebe que precisa se reorganizar, pois não mais haverá a presença desse indivíduo em suas vidas no futuro. Surge a necessidade de rever toda a dinâmica familiar, o que causa um grande desconforto, pois, além de lidar com a perda no âmbito sentimental, é preciso lidar com as questões práticas da vida e o enfrentamento no meio social, levando tempo para que a família se restabeleça de forma estável e aprenda a lidar com a perda e as questões emergentes (4).

Esses dilemas estão diretamente ligados ao conceito de eutanásia, uma vez que ao decidir a favor ou contra tal procedimento, a família se vê diante da situação de tolerância, assistindo à pessoa antes saudável entrando em estado de declínio, submetendo-se a tratamentos pouco eficazes à recuperação da sua saúde, pois já elucidam a impossibilidade de cura para tal. Essa opção é cogitada em casos extremos, em que o indivíduo se encontra 
em estado vegetativo e irreversível, tendo sua vida mantida através de aparelhos; porém, o procedimento deve ser permitido por lei. O próprio paciente, em casos que ainda se encontre consciente, tem o direito de escolher se irá continuar com o tratamento ou solicitar a sua interrupção. A equipe médica deve respeitar a decisão do paciente e providenciar documentos que os isentem de qualquer responsabilidade perante tal determinação (21).

Essas mesmas sensações são vivenciadas pela família do usuário de drogas quando há a necessidade de internação de um de seus membros ou quando a família resiste impedindo os demais de se envolverem na tentativa de resgatar e restabelecer o usuário. Todavia, mesmo com a intervenção familiar, o dependente de drogas tem o direito de escolher se irá se submeter a algum tratamento.

Em um processo de diagnóstico de doença terminal, assim como o envolvimento com as drogas, os familiares buscam formas de manterem viva a esperança de que algo ainda poderá acontecer e essa pessoa sobreviverá. Dessa premissa recorrem a outros médicos e novas formas de tratamento, fazendo com que o indivíduo se submeta a elas. A família tem a necessidade de saber que fizera tudo o que podia para salvar aquele que ama para que, quando da sua morte ou o desejo de prosseguir com o uso de drogas, sintam que isso ocorreu porque realmente já não havia mais solução para tal condição de saúde em que o indivíduo se encontrava (4).

No caso da morte, a família interpreta como algo natural, sem a interferência de terceiros; no caso das drogas há a desesperança e o sentimento de fracasso diante do ocorrido. Em ambas situações é preciso aguardar até o último instante, pois há sempre a expectativa de melhora, por menor que seja (1).

A família, tanto do paciente terminal quanto do usuário de drogas, passa por um período de desgaste físico e mental, enquanto vivencia a situação de degradação de seus entes queridos. Diante da finitude da vida por causas que fogem ao controle da medicina, a família precisa passar por um processo de elaboração de seus sentimentos para chegar ao estado de aceitação de que não há mais nada a ser feito. Não obstante, vivenciam ao lado daquele que ama seus últimos momentos de vida, tentando passar a ele tranquilidade, além de auxiliá-lo também para que a experiência seja menos dolorosa. (4).

No tocante ao usuário de drogas, as famílias vivenciam sentimento de culpa, impotência, desamparo e emoções semelhantes às dos familiares de pacientes terminais, pois há nessa situação também uma perda. O usuário de drogas transforma-se física e mentalmente, deixa de ser o filho, pai, mãe, conhecido e torna-se uma pessoa diferente, que em determinados casos não aceita ajuda para se tratar e sucumbe a um mundo sombrio e sem volta, causando preocupação para aqueles que só querem o seu bem (20).

Outubro, 2016:2(Edição Especial):1-13. 
A Bioética possui como um de seus princípios fundamentais o da autonomia, ocupando-se, principalmente, com a defesa dos direitos do paciente enquanto pessoa individual e com poder de decisão sobre o próprio tratamento. Estando essa pessoa em estado normal de consciência, apta a decidir o que considera ser melhor para ela, faz com que as decisões quanto aos tratamentos que não quer se submeter sejam documentadas para que a equipe médica fique isenta de qualquer responsabilidade referentes a possíveis consequências. Constitui dever do profissional médico utilizar-se de seus conhecimentos e aparatos disponíveis para preservar a vida de qualquer ser humano que o procure necessitando de seus cuidados (22).

Os usuários de drogas são responsáveis pelo início, desenvolvimento e soluções de seus problemas relacionados à drogadição, porém precisam da motivação adequada para que essa última ocorra. Após tornarem-se dependentes de substâncias, passam a acreditar que não conseguem viver sem estar sob o efeito das mesmas devido aos episódios negativos que experimentam diante da abstinência (8).

Fica evidente que em ambos os casos os indivíduos possuem direito ao tratamento, porém, é necessário que haja o consentimento deles para que o procedimento aconteça.

\section{CONCLUSÃO}

A morte constitui uma questão geradora de angústia e sofrimento para o homem, que está habituado à busca pelos ganhos e prazeres que a vida pode lhe oferecer; ao deparar-se com a sensação de possibilidade de perda de algo ou alguém, vê-se diante de dilemas e incertezas.

A eutanásia, vista como alternativa de colocar fim ao sofrimento de um ser amado é um procedimento polêmico, pois nem todos a interpretam como algo positivo. A morte, assim como a vida, é explanada costumeiramente como um evento destinado a ocorrer de forma natural, sem a interferência de terceiros.

A questão das drogas surge para amarrar esse "deixar de viver". A degradação causada por essas substâncias é encarada como um meio de deixar se levar para mais próximo da morte, seguindo um caminho consentido por aquele que se submete ao uso nocivo e consciente de algo que não lhe faz bem.

Nos dois contextos há o sofrimento por parte do paciente/usuário e seus familiares, que buscam a recuperação do ser amado e frustram-se diante das incertezas e da sensação de impotência ao se depararem com uma condição irreversível de uma doença ou deterioração física.

Outubro, 2016:2(Edição Especial):1-13. 
Escrever sobre tal tema tornou-se um desafio, pois há pouco material voltado ao assunto e a temática nos inclina a pensar em nossas próprias vidas, em nossa finitude, em nossos hábitos e atitudes diante do que o mundo nos oferece.

Tendo em vista que viver é um desafio imposto a cada ser vivente sobre a Terra, independentemente de sua vontade, é preciso compreender a particularidade de cada um quando os mesmos se encontram em situações negativas, sem perspectivas futuras, compreender que viver é um ato de dignidade e que para algumas pessoas a perda dessa dignidade e a total dependência já é um morrer silencioso.

\section{REFERÊNCIAS}

1. Santo CCE, Lima CFM, Silva LA, Costa RF, Rodrigues BMRD, PachecoSTA. Produção científica de enfermagem acerca da eutanásia: revisão integrativa da literatura. Revista de Pesquisa Cuidado é Fundamental Online. [periódico na internet] 2013 [acesso em 10 mar 2015];6(3):1231-42. Disponível em:

http://www.seer.unirio.br/index.php/cuidadofundamental/article/view/3061/pdf_138.

2. Cruz TFS. Psicologia hospitalar e eutanásia. Revista da Sociedade Brasileira de Psicologia Hospitalar. [periódico na internet]2005 [acesso em 15 mar 2015];8(2):17-23. Disponível em: http://pepsic.bvsalud.org/scielo.php?script=sci_arttext\&pid=S151608582005000200003.

3. Queiroz VE. A questão das drogas ilícitas no Brasil. [Monografia]Florianópolis: Universidade Federal de Santa Catarina; 2008 [acesso em 15 set 2015]. Disponível em: http://tcc.bu.ufsc.br/Economia292028.

4. Mendes JA, Lustosa MA, Andrade MCM. Paciente terminal, família e equipe de saúde. Revista da Sociedade Brasileira de Psicologia Hospitalar. [periódico na internet] 2009 [acesso em 10 mar 2015];12(1):151-73. Disponível em:

http://pepsic.bvsalud.org/scielo.php?script=sci_arttext\&pid=\$1516-08582009000100011.

5. Gonçalves MS, Miranda PCGA. Vivenciar o morrer de um ente querido: parece que estamos morrendo junto. [Monografia]Goiânia: Universidade Católica de Goiás;2004 [acesso em 29 mar 2015]. Disponível em:

www.ucg.br/ucg/Institutos/nepss/monografia/monografia_09.pdf.

6. Magalhaes MV, Melo SCA. Morte e luto: o sofrimento do profissional da saúde. Revista Psicologia e Saúde em Debate. [periódico na internet] 2015 [acesso em 24 ago 2016]; 1(1):

Outubro, 2016:2(Edição Especial):1-13. 
65-77. Disponível em: https://psicodebate.files.wordpress.com/2014/12/5-magalhc3a3esmelo-2015.pdf.

7. Santos DA, Almeida ERP, Silva FF, Andrade LHC, Azevedo LA, Neves NMBC. Reflexões bioéticas sobre a eutanásia a partir de caso paradigmático. Revista Bioética. [periódico na internet]2014 [acesso em 15 mar 2015];2(22):367-72. Disponível em:

http://revistabioetica.cfm.org.br/index.php/revista_bioetica/article/viewFile/921/105.

8. Daumas JSP. As dificuldades enfrentadas pela estratégia saúde da família no cuidado à saúde do dependente químico. [Dissertação] Rio de Janeiro: Universidade Estácio de Sá;2012 [acesso em 24 jan 2016]. Disponível em:http://portal.estacio.br/media/4258930/jane\%20do\%20socorro\%20pantoja\%20daumas.p df.

9. Batista RS, Schramm FR. Eutanásia: pelas veredas da morte e da autonomia. Ciência e Saúde Coletiva. [periódico na internet].2004 [acesso em 10 ago 2015];1(9):31-41. Disponível em: http://www.scielo.br/scielo.php?pid=\$1413-81232004000100004\&script=sci_arttext.

10. Domingues G. R. et al. A atuação do psicólogo no tratamento de pacientes terminais e seus familiares. Revista da Sociedade Brasileira de Psicologia Hospitalar. [periódico na internet] 2013 [acesso em 12 mar 2015];11(1):02-24. Disponível em:

http://pepsic.bvsalud.org/scielo.php?pid=S1677-74092013000100002\&script=sci_arttext.

11. Carlini EA, Nappo SA, Galduróz JCF, Noto AR. Drogas psicotrópicas: o que são e como agem. RevistalMESC. [periódico na internet]2001[acesso em 02 nov 2015];(3):9-35.

Disponível em:

http://www.imesc.sp.gov.br/pdf/artigo\%201\%20\%20DROGAS\%20PSICOTR\%C3\%93PICAS \%200\%20QUE\%20S\%C3\%830\%20E\%20COMO\%20AGEM.pdf.

12. Lima DS. As ações dos profissionais de saúde da atenção básica junto a usuários com problemas decorrentes do uso de álcool e outras drogas. [Dissertação]Florianópolis: Universidade Federal de Santa Catarina; 2009 [acesso em 01 out 2015]. Disponível em: http://psiclin.ufsc.br/files/2010/11/Disserta\%C3\%A7ao_D\%C3\%A1lberti_Lima._Versao_final. pdf.

13. Nery Filho A, Mcrae E, Tavares LA, Nunez ME, Rego M. As drogas na contemporaneidade: perspectivas clínicas e culturais. Salvador: Centro de Estudos e Terapia do Abuso de Drogas - CETAD/UFBA; 2012.

Outubro, 2016:2(Edição Especial):1-13. 
14. Medeiros KT, Maciel SC, Sousa PF, Tenório-Souza FM, Dias CCV. Representações sociais do uso e abuso de drogas entre familiares de usuários. Psicologia em Estudo. [periódico na internet]2013 [acesso em 17 set 2015];18(2):269-79. Disponível em: http://www.scielo.br/scielo.php?script=sci_arttext\&pid=S1413-73722013000200008.

15. Zemel MLS. O papel da família no tratamento da dependência. Revista IMESC. [periódico na internet] 2001 [acesso em 04 out 2015];(3):43-63. Disponível em: http://www.imesc.sp.gov.br/pdf/artigo\%203\%20-

\%200\%20PAPEL\%20DA\%20FAM\%C3\%8DLIA\%20NO\%20TRATAMENTO\%20DA\%20DEP END\%C3\%8ANCIA.pdf.

16. Melo PF, Paulo MAL. A importância da família na recuperação do usuário de álcool e outras drogas. Saúde Coletiva em Debate. [periódico na internet]2012 [acesso em 04 out 2015];2(1):41-51. Disponível em:

http://fis.edu.br/revistaenfermagem/artigos/vol02/artigo09.pdf.

17. AlmeidaRCA. O SUS e o desafio imposto pelas drogas. Psicanálise \& Barroco em revista. [periódico na internet].2009[acesso em 04out 2015];7(2):179-84. Disponível em: http://www.psicanaliseebarroco.pro.br/revista/revistas/14/P\&Brev14Almeida.pdf.

18. Nogueira JG. A importância da família na problemática da drogadição com adolescentes sob o olhar da análise do comportamento. [Trabalho de Conclusão de Curso]Bebedouro: Faculdades Integradas Fafibe; 2009 [acesso em 27 out 2015]. Disponível em:

http://unifafibe.com.br/revistasonline/arquivos/revistapsicologia/sumario/14/06122010140050 .pdf.

19. Maciel SC, Melo JRF, Dias CCV, Silva GLS, Gouveia YB. Sintomas depressivos em familiares de dependentes químicos. Revista Psicologia:Teoria e Prática. [periódico na internet] 2014 [acesso em 25 out 2015];16(2):18-28. Disponível em: http://editorarevistas.mackenzie.br/index.php/ptp/article/viewFile/6229/5013.

20. Maruiti MR, Galdeano LE, Farah OGD. Ansiedade e depressão em familiares de pacientes internados em unidade de cuidados intensivos. Acta Paulista de Enfermagem. [periódico na internet]2008[ acesso em 25 out 2015];21(4):636-42. Disponível em: http://www.redalyc.org/articulo.oa?id=307023829016.

21. Corvino JDF. Eutanásia: um novo paradigma. Revista Seção Judiciária do Rio de Janeiro.[periódico na internet]2013 [acesso em 29 mar 2015];20(37):53-73. Disponível em: www4.jfrj.jus.br/seer/index.php/revista_sjrj/article/view/417/353.

Outubro, 2016:2(Edição Especial):1-13. 


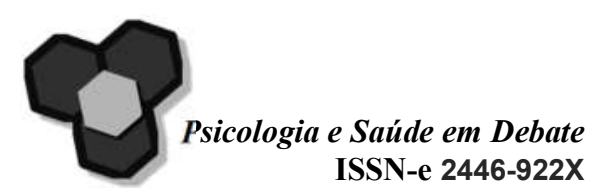

22. Clotet J. Reconhecimento e institucionalização da autonomia do paciente: um estudo da The Patiente Self-Determmination ACT. Revista Bioética. 1993 [acesso em 24 jan 2016];1(2):157-64. Disponível em:

http://revistabioetica.cfm.org.br/index.php/revista_bioetica/article/view/494.

Outubro, 2016:2(Edição Especial):1-13. 